\title{
A Case of Leprosy in an African Albino
}

\author{
H. W. WHEATE \\ Government Leprosy Hospital, \\ Chazi, Tanzania
}

\begin{abstract}
Albinism is not common in Tanzania, the average prevalence being of the order of $1 / 10,000$. Since the prevalence of leprosy is about $10 / 1000$, the chance of leprosy being associated in the same individual with albinism would be about 1 in 100,000 .
\end{abstract}

\section{CASE REPORT}

The following report of the occurrence of tuberculoid leprosy in an albino is of interest since, as far as can be ascertained, no such case has been reported previously.

A young adult male peasant (age between 26 and 30 years) from the rural part of Morogoro District, sought admission to the Chazi leprosarium on 20 May, 1971 , because of plantar ulcers on both feet. He said he had had leprosy since 1961 , for which he had received treatment irregularly at an out-patient clinic.

Clinical examination disclosed incomplete albinism, with nystagmus. There were a number of small pigmented areas on the skin. No malignant changes were seen. Two residual tuberculoid lesions were present in the left loin, in which there was diminished sensation to light touch. The ulnar-innervated muscles of the right hand were wasted, and there was obvious absorption of the bones of the ungual and intermediate phalanges of the $3 \mathrm{rd}, 4$ th and 5 th fingers. In the left hand there was absorption of the ungual phalanges, and scars of old injuries. The toes of both feet had been lost from ulceration, and ulcers were present over the heads of both first metatarsals. The right lateral popliteal nerve was enlarged. The skin smears showed no leprosy bacilli.

The plantar ulcers healed in 3 months with rest and the wearing of sandals with microcellular rubber in-soles.

\section{Acknowledgement}

My thanks are due to the Chief Medical Officer, Tanzanian Ministry of Health and Social Welfare, for permission to publish this note. 